\title{
Model and Frequency Control for Three-Phase Wireless Power Transfer System
}

\author{
Chenyang Xia, Yuling Liu, Kezhang Lin, and Guangqing Xie \\ School of Information and Electrical Engineering, China University of Mining and Technology, Xuzhou 221116, China \\ Correspondence should be addressed to Chenyang Xia; linkz1992@163.com
}

Received 19 May 2016; Revised 3 September 2016; Accepted 8 September 2016

Academic Editor: Antonino Laudani

Copyright (c) 2016 Chenyang Xia et al. This is an open access article distributed under the Creative Commons Attribution License, which permits unrestricted use, distribution, and reproduction in any medium, provided the original work is properly cited.

\begin{abstract}
In order to the eliminate the "dead spot" in the traditional three-phase wireless power transfer (WPT) system, a three-phase WPT system with an asymmetric magnetic circuit is presented in this paper. Additionally, mathematical model of the system is established and the system parameters are optimized. Based on the fact that the resonant frequency and efficiency are greatly varied with the load, a method based on impedance conversion is further proposed to improve the frequency stability and system efficiency. Finally, simulation and experimental results show that the proposed method is reliable and feasible to eliminate the "dead spot."
\end{abstract}

\section{Introduction}

Wireless power transfer (WPT) can transmit electric energy from the power sources to the loads without any wire between the two sides, which offers advantages in terms of flexibility, reliability, and safety [1-4]. Therefore, it has been widely used in some special fields, including wireless power desktop supply platform, two-way power supply for tram [5], and mining application [6].

Most of the previous research is limited in single-phase WPT system. With rapid development of electrical equipment, the three-phase WPT system has been further developed [7-9]. A new three-phase and bidirection WPT system that is suitable for rapid charging of EVs is presented [10]. A new three-phase bipolar inductive power transfer system can provide power across the entire width of a roadway [11]. However, a three-phase WPT system usually suffers the "dead spot" problem in pick-up side. Some researchists present a solution about the pick-up "dead spot" in a three-phase WPT system [12-14]. It is suitable for desk wireless power supply system. There will be a tiny pick-up voltage when the load is exactly in the pick-up "dead spot." Besides, the system will automatically switch one-phase to another to avoid "dead spot" problem. However, it suffers low efficiency, complicated operation, and extra detection circuit. Furthermore, the impacts of the load variation on system stability and efficiency are not considered in this system. Some papers did some research on the efficiency of the three-phase WPT system from magnetic structure and system modeling [15]. Therefore, further studies on the three-phase WPT system, especially the dead spot elimination, frequency stabilization, and efficiency improvement are strongly required. A lot of papers study the method of impedance conversion $[16,17]$. However, this method is rarely studied to control frequency stability in three-phase WPT system.

In this paper, to eliminate the "dead spot" in the traditional three-phase WPT system with symmetric circuit, a new asymmetric magnetic circuit is studied. Mathematical model of the system is established to optimize the system parameters. In addition, an impedance conversion based method is proposed to improve the frequency stability and system efficiency as both the resonant frequency and efficiency are heavily affected by the load variation. An experimental prototype is established to verify the validity of the proposed method. Simulation and experimental results indicate that the "dead spot" can be always eliminated regardless of the load position.

\section{Typical Three-Phase WPT System Analysis}

2.1. Overview of Three-Phase Wireless Power Transfer System. A typical three-phase WPT system with a symmetrical 


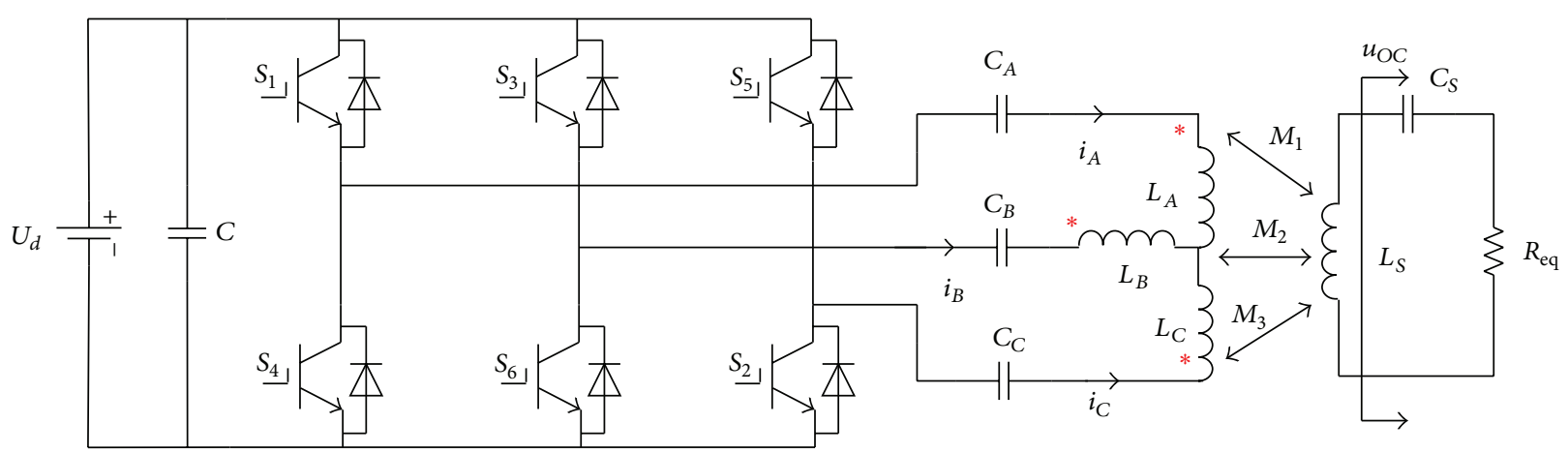

FIGURE 1: Typical symmetrical magnetic three-phase WPT system.

magnetic circuit is shown in Figure 1. This system consists of DC power supply $\left(U_{d}\right)$, high frequency inverter $\left(S_{1} \sim S_{6}\right)$, primary side $\left(L_{A}, L_{B}, L_{C}\right.$ and $\left.C_{A}, C_{B}, C_{C}\right)$, and pick-up side $\left(L_{s}\right.$ and $\left.C_{s}\right)$ as well as load $\left(R_{\text {eq }}\right)$. Meanwhile, $*$ is dotted terminal of the three-phase primary coils. The mutual inductances between primary side and pick-up side are denoted by $M_{1}$, $M_{2}$, and $M_{3}$. Primary-side power converter generates a threephase symmetrical high frequency sinusoidal current in the primary coils. Then the pick-up side, which is magnetically coupled to primary side, obtains power from the primary side to supply load through power conversion.

It has been confirmed that such a system in Figure 1 suffers from "dead spot" problem in the pick-up side. And a new three-phase WPT system with asymmetrical magnetic circuit which can effectively eliminate the "dead spot" is presented [18]. However, system parameters optimization and the influence of load variation on system stability were both ignored in this paper.

2.2. Characteristic Analysis of "Dead Spot". By the analysis of three-phase full-bridge inverter, currents in the three primary coils, with the same value of amplitude $I_{0}$, can be written as

$$
\begin{aligned}
& i_{A}=I_{0} e^{j \omega t}, \\
& i_{B}=I_{0} e^{j \omega t+j \pi 2 / 3}, \\
& i_{C}=I_{0} e^{j \omega t+j \pi 4 / 3} .
\end{aligned}
$$

The pick-up voltage of secondary coil is

$$
\begin{aligned}
u_{\mathrm{OC}} & =u_{A S}+u_{B S}+u_{C S} \\
& =j \omega M_{1} i_{A}+j \omega M_{2} i_{B}+j \omega M_{3} i_{C} \\
& =j \omega I_{0} e^{j \omega t}\left(M_{1}+e^{j \pi 2 / 3} M_{2}+e^{j \pi 4 / 3} M_{3}\right),
\end{aligned}
$$

where $u_{A S}, u_{B S}$, and $u_{C S}$ are the pick-up voltages of the secondary coil induced from three primary coils.

According to (2), the vector graph of pick-up voltage $u_{O C}$ is shown in Figure 2.

From (2) and Figure 2, it can be assured that pick-up $u_{\mathrm{OC}}$ equals zero when three mutual inductances $M_{1}-M_{3}$ have the same value. That is, "dead spot" exists when secondary coil is located in the center of three primary coils.

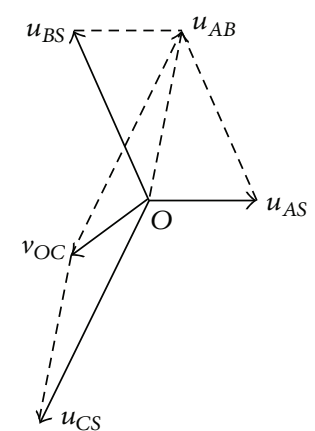

FIGURE 2: Vector graph of pick-up voltage $u_{O C}$ in symmetric threephase WPT system.

\section{New Type of Three-Phase WPT System with Asymmetric Magnetic Circuit}

3.1. Analysis of Eliminating "Dead Spot". In order to solve the problem of "dead spot" in three-phase WPT system, a three-phase WPT system with an asymmetric magnetic circuit is proposed in Figure 3. The dotted terminal of $C$ phase (the third phase of three phase coils) is reversed so that the magnetic circuit becomes asymmetric.

Figure 4 shows the equivalent model of the pick-up side. In this case, the pick-up voltage $V_{O C}$ of the pick-up side can be written as

$$
\begin{aligned}
u_{\mathrm{OC}}^{\prime} & =u_{A S}+u_{B S}-u_{C S} \\
& =j \omega M_{1} i_{A}+j \omega M_{2} i_{B}-j \omega M_{3} i_{C} \\
& =j \omega I_{P} e^{j \omega t}\left(M_{1}+e^{j \pi 2 / 3} M_{2}-e^{j \pi 4 / 3} M_{3}\right),
\end{aligned}
$$

where $I_{P}$ is the current amplitude and $\omega$ is the work frequency of the system.

It can be seen from (3) that, regardless of the value of three mutual inductances $M_{1}, M_{2}$, and $M_{3}$, "dead spot" never exists compared to the traditional symmetrical magnetic circuit, ensuring that the load on any position can achieve efficient power transmission. 


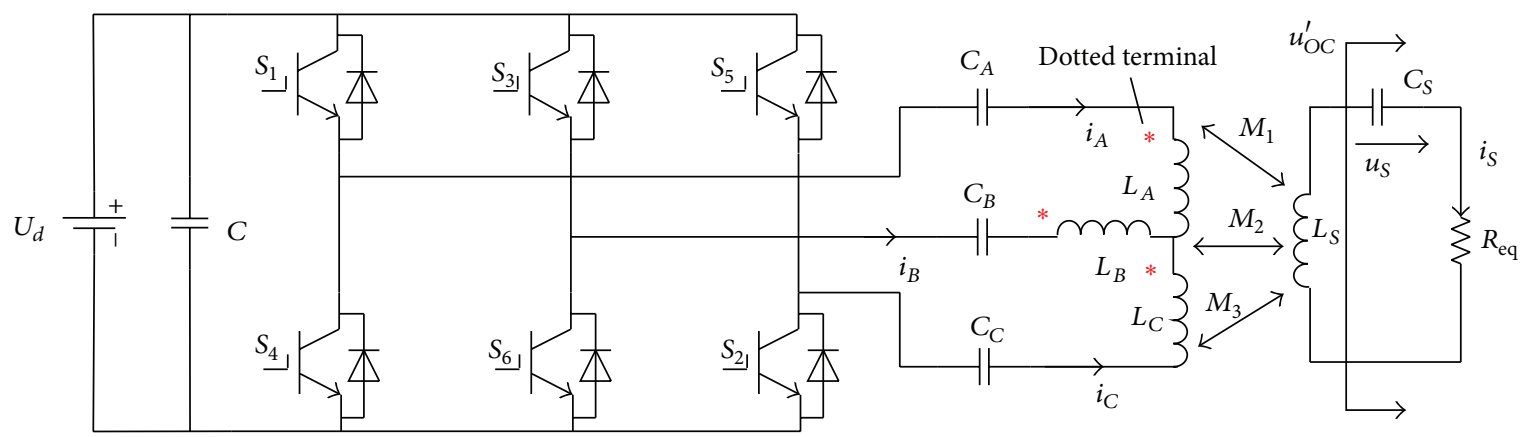

FIgURE 3: Three-phase WPT system with asymmetric magnetic circuit.

3.2. Design and Optimization of Parameters. As shown in Figure 3, the instantaneous value of current flowing in the three primary coils can be represented by

$$
\begin{aligned}
& i_{A}=I_{P} \sin (\omega t)=I_{P} \angle 0^{\circ}, \\
& i_{B}=I_{P} \sin \left(\omega t+120^{\circ}\right)=I_{P} \angle 120^{\circ}, \\
& i_{C}=I_{P} \sin \left(\omega t+240^{\circ}\right)=I_{P} \angle 240^{\circ},
\end{aligned}
$$

where $i_{A}, i_{B}$, and $i_{C}$ are all the current instantaneous value.

In Figure $4, L_{S}$ is self-inductance of secondary windings. $C_{S}$ is the pick-up resonant capacitor. $C_{S}$ can be expressed as

$$
C_{S}=\frac{1}{\omega^{2} L_{S}}
$$

The pick-up current $C_{S}$ is

$$
I_{S}=\frac{\omega M_{1} I_{P} \angle 0^{\circ}+\omega M_{2} I_{P} \angle 120^{\circ}-\omega M_{3} I_{P} \angle 240^{\circ}}{R_{\mathrm{eq}}} .
$$

According to Ohm's law, a phase of primary coils can be represented by

$$
I_{P} Z_{A}=\omega M_{1} I_{S}
$$

where $Z_{A}$ is the reflected impedance. By (6) and (7), $Z_{A}$ can be expressed as

$$
\begin{aligned}
Z_{A} & =\frac{\omega^{2} M_{1}}{R_{\mathrm{eq}}}\left(M_{1}+M_{2} \angle 120^{\circ}-M_{3} \angle 240^{\circ}\right) \\
& =\frac{\omega^{2} M_{1}}{R_{\mathrm{eq}}}\left[M_{1}-\frac{1}{2} M_{2}+\frac{1}{2} M_{3}\right. \\
& \left.+\left(\frac{\sqrt{3}}{2} M_{2}+\frac{\sqrt{3}}{2} M_{3}\right) j\right]
\end{aligned}
$$

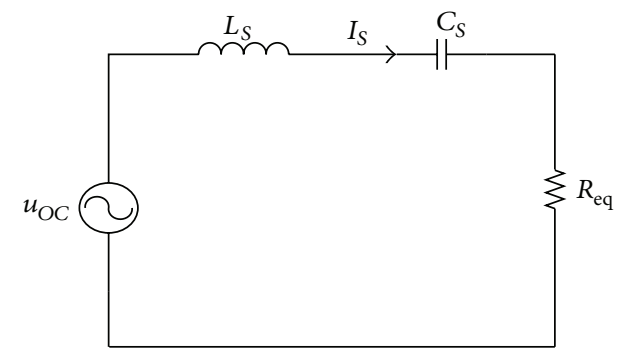

FIgURE 4: Equivalent model of the secondary circuit.

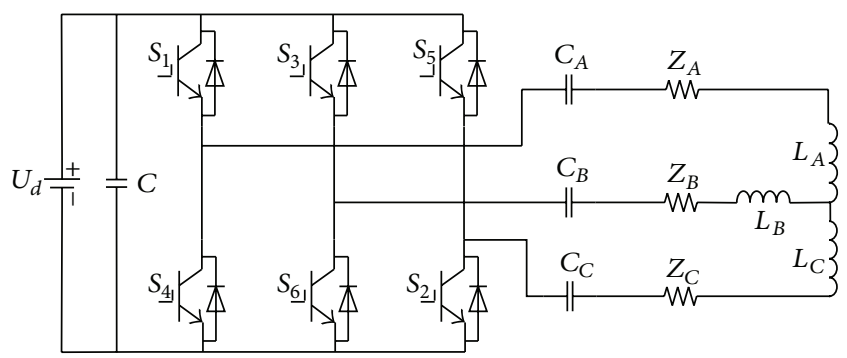

FIGURE 5: Primary equivalent inductance coupling model of asymmetric circuit.

So, $Z_{B}$ and $Z_{C}$ can be expressed as

$$
\begin{aligned}
Z_{B} & =\frac{\omega^{2} M_{2}}{R_{\mathrm{eq}}}\left[M_{2}-\frac{1}{2} M_{1}+\frac{1}{2} M_{3}\right. \\
& \left.-\left(\frac{\sqrt{3}}{2} M_{1}+\frac{\sqrt{3}}{2} M_{3}\right) j\right], \\
Z_{C} & =\frac{\omega^{2} M_{3}}{R_{\mathrm{eq}}}\left[M_{3}+\frac{1}{2} M_{1}+\frac{1}{2} M_{2}\right. \\
& \left.+\left(\frac{\sqrt{3}}{2} M_{2}-\frac{\sqrt{3}}{2} M_{1}\right) j\right] .
\end{aligned}
$$

Based on mutual inductance coupling principle, the pickup side can be reflected into primary side. The equivalent model is shown in Figure 5. According to the actual demand 
of the system, the real part of $Z_{A}, Z_{B}$, and $Z_{C}$ should be more than zero to ensure the system resonance; then

$$
\begin{aligned}
& \operatorname{Re}\left(Z_{A}\right)=M_{1}-\frac{1}{2} M_{2}+\frac{1}{2} M_{3}>0, \\
& \operatorname{Re}\left(Z_{B}\right)=M_{2}+\frac{1}{2} M_{3}-\frac{1}{2} M_{1}>0, \\
& \operatorname{Re}\left(Z_{C}\right)=M_{3}+\frac{1}{2} M_{1}+\frac{1}{2} M_{2}>0 .
\end{aligned}
$$

The sums between imaginary parts of $Z_{A}, Z_{B}, Z_{C}$, and $\omega L$ should be more than zero.

$$
\begin{aligned}
\operatorname{Im}\left(Z_{A}+\omega L_{A}\right)= & \frac{\omega^{2} M_{1}}{R_{\mathrm{eq}}}\left(\frac{\sqrt{3}}{2} M_{2}+\frac{\sqrt{3}}{2} M_{3}\right)+\omega L_{A} \\
> & 0, \\
\operatorname{Im}\left(Z_{B}+\omega L_{B}\right)= & \frac{\omega^{2} M_{2}}{R_{\mathrm{eq}}}\left(-\frac{\sqrt{3}}{2} M_{1}-\frac{\sqrt{3}}{2} M_{3}\right) \\
& +\omega L_{B}>0, \\
\operatorname{Im}\left(Z_{C}+\omega L_{C}\right)= & \frac{\omega^{2} M_{3}}{R_{\mathrm{eq}}}\left(\frac{\sqrt{3}}{2} M_{2}-\frac{\sqrt{3}}{2} M_{1}\right)+\omega L_{C} \\
> & 0 .
\end{aligned}
$$

From (10), when mutual inductance $M_{2} / 2<M_{1}<2 M_{2}$, (11) can be simplified as

$$
\begin{aligned}
& L_{B}>\frac{\sqrt{3}}{2} \frac{\omega M_{2}}{R_{\mathrm{eq}}}\left(M_{1}+M_{3}\right), \\
& L_{C}>\frac{\sqrt{3}}{2} \frac{\omega M_{3}}{R_{\mathrm{eq}}}\left(M_{1}-M_{2}\right) .
\end{aligned}
$$

Assuming that $L_{A}=L_{B}=L_{C}=L$, the self-inductance of the primary windings meets (13) only.

$$
L>\frac{\sqrt{3}}{2} \frac{\omega M_{2}}{R_{\mathrm{eq}}}\left(M_{1}+M_{3}\right) .
$$

In summary, the mutual inductance and self-inductance of three-phase WPT system with an asymmetric magnetic circuit should meet the following equation:

$$
\begin{aligned}
\frac{M_{2}}{2} & <M_{1}<2 M_{2}, \\
L & >\frac{\sqrt{3}}{2} \frac{\omega M_{2}}{R_{\mathrm{eq}}}\left(M_{1}+M_{3}\right) .
\end{aligned}
$$

When the primary side is at resonance, (15) should meet

$$
\begin{aligned}
& \operatorname{Im}\left(Z_{A}+j \omega L_{A}+\frac{1}{j \omega C_{A}}\right)=0, \\
& \operatorname{Im}\left(Z_{B}+j \omega L_{B}+\frac{1}{j \omega C_{B}}\right)=0, \\
& \operatorname{Im}\left(Z_{C}+j \omega L_{C}+\frac{1}{j \omega C_{C}}\right)=0 .
\end{aligned}
$$

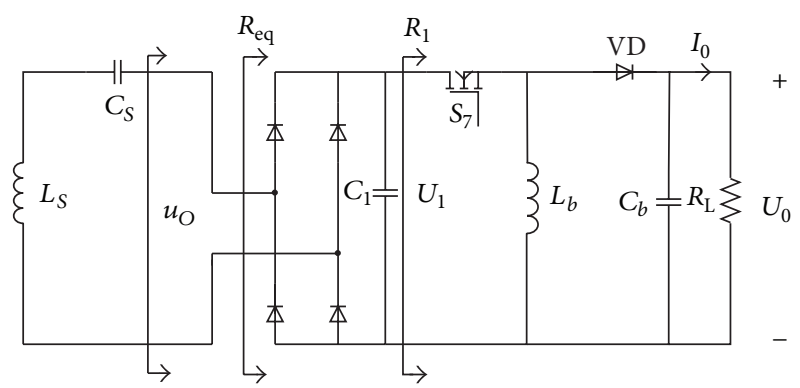

FIGURE 6: Impedance conversion circuit.

So the resonant capacitor of the three-phase primary winding can be written as

$$
\begin{aligned}
& C_{A}=\frac{2 R_{\mathrm{eq}}}{\sqrt{3} \omega^{3} M_{1}\left(M_{2}+M_{3}\right)+2 R_{\mathrm{eq}} \omega^{2} L}, \\
& C_{B}=\frac{2 R_{\mathrm{eq}}}{-\sqrt{3} \omega^{3} M_{2}\left(M_{1}+M_{3}\right)+2 R_{\mathrm{eq}} \omega^{2} L}, \\
& C_{C}=\frac{2 R_{\mathrm{eq}}}{\sqrt{3} \omega^{3} M_{3}\left(M_{2}-M_{1}\right)+2 R_{\mathrm{eq}} \omega^{2} L} .
\end{aligned}
$$

Obviously, actual operation frequency is affected by load $R_{\text {eq. }}$. That is, there is a one-to-one correspondence between corresponding direct parameters (inductances and capacitances) and a load value. However, the value of load is usually variational due to heat and temperature variation. So, common platform is more meaningful for three-phase WPT system.

3.3. The Analysis of Frequency Stability. From (16), the values of the primary resonance capacitor are associated with $M, R_{\text {eq }}$, and $\omega$. Fixed and variable frequency control are two main control strategies. It is obvious that fixed frequency control is more suitable for this system. If the load is placed in the center of three-phase primary coils, the mutual inductance $M$ is fixed. Therefore, the values of the primary resonance capacitor are only associated with $R_{\text {eq }}$. In practical threephase WPT system, power transfer and efficiency are greatly affected by the change in resonant frequency due to the load variance. To solve the problem mentioned above, a fixed frequency control strategy based on impedance conversion was presented in next section.

\section{Frequency Stability Method Based on Impedance Conversion}

4.1. Basic Principle of Impedance Conversion. In the pickup side, for the sake of achieving the frequency stability of system, a rectifier-filter circuit and DC/DC converter are introduced to achieve the fixed frequency of system, which can maintain the equivalent impedance of load through regulating the duty cycle of DC chopper.

The schematic circuit of impedance conversion based on the Buck-Boost converter is shown in Figure 6, where 
$R_{1}$ is the equivalent impedance after rectifier-filter circuit regulation and $R_{\text {eq }}$ is the equivalent impedance across the pick-up power compensation part.

As shown in Figure 6, pick-up coil generates a direct voltage $U_{1}$ after resonance compensation and rectifier-filter circuit. Then, this voltage $\left(U_{1}\right)$ can provide power for load $\left(R_{L}\right)$ across the Buck-Boost converter, so that the output voltage of load becomes $U_{o}$.

4.2. Theoretical Derivation. Assume that Buck-Boost circuits work in the soft-switching mode and the switching loss is ignored. To simplify the system, the load $R_{L}$ is a resistant load; then

$$
\frac{U_{1}^{2}}{R_{1}}=\frac{U_{0}^{2}}{R_{L}} .
$$

When the Buck-Boost circuit works under the continuous current mode, the relationship between $U_{0}$ and $U_{1}$ can be expressed as

$$
U_{0}=\frac{\delta}{1-\delta} U_{1}
$$

where $\delta$ is the duty cycle of switch.

From (17) and (18), the relationship between $R_{1}$ and $R_{L}$ can be given by

$$
R_{1}=\frac{(1-\delta)^{2}}{\delta^{2}} R_{L} .
$$

The equivalent ac resistance $R_{\mathrm{eq}}$ for the rectifier with capacitive filter [19] is given by

$$
R_{\mathrm{eq}}=\frac{8}{\pi^{2}} R_{1} .
$$

The relation between the duty ratio of switch $\delta$ and the load $R_{L}$ can be calculated from (19) and (20).

$$
\delta=\frac{2 \sqrt{2}}{2 \sqrt{2}+\pi \sqrt{R_{\mathrm{eq}} / R_{L}}},
$$

where $\delta$ is in the range $0 \sim 1$. The relationship between duty cycle $\delta$ and variable load $R_{L}$ is shown in Figure 7 when equivalent load $R_{\mathrm{eq}}$ is held constant.

From Figure 7, for a given $R_{L}$, there will be $\delta$ to hold $R_{\text {eq }}$ constant.

\section{Simulation and Experimental Results}

The viability of the proposed system is verified by simulation and experiments. The prototype system is shown in Figure 8. For the following confirmatory experiments, $10 \Omega$ load will be powered by a $500 \mathrm{~V}$ DC voltage source. The system resonant frequency is $20 \mathrm{kHz}$. The three primary coils inductors $L_{A}, L_{B}$, and $L_{C}$ are $91.78 \mathrm{mH}$. The pick-up coil $L_{S}$ is $67 \mathrm{mH}$. The mutual inductances of $M_{1}, M_{2}$, and $M_{3}$ are $30 \mathrm{mH}$. According to (5), the capacitances of secondary

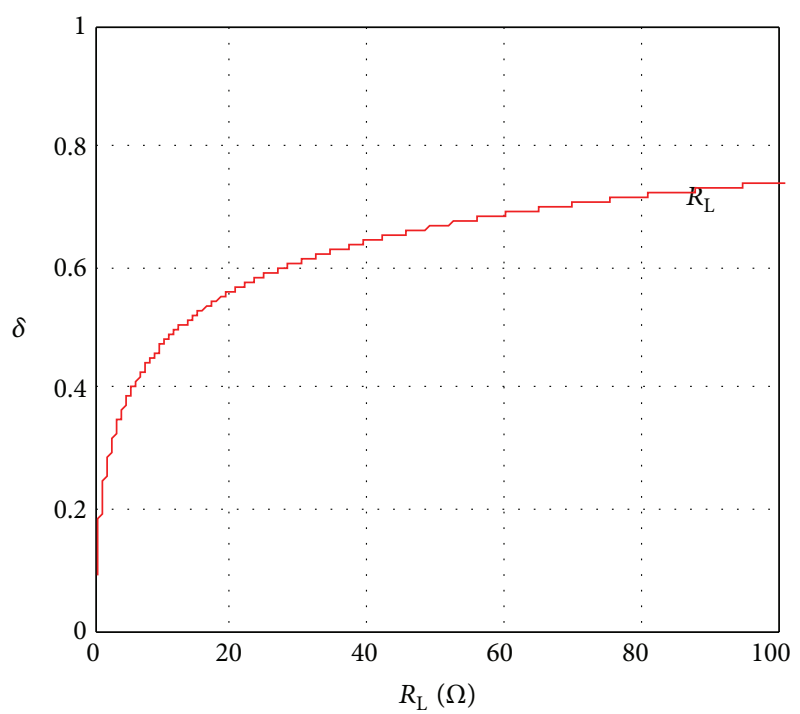

Figure 7: One-to-one correspondence between duty cycle $\delta$ and variable load $R_{L}$ for constant equivalent load $R_{\mathrm{eq}}$.

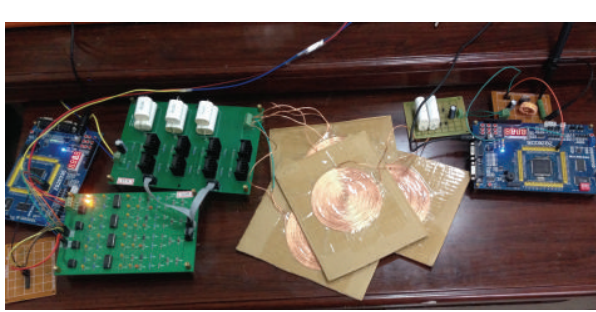

Figure 8: Experimental platform.

side can be calculated as $0.94 \mu \mathrm{F}$. Furthermore, from (16), the capacitances of primary side $C_{A}, C_{B}$, and $C_{C}$ are $0.565 \mu \mathrm{F}$, $0.906 \mu \mathrm{F}$, and $0.686 \mu \mathrm{F}$, respectively.

In Figures 9-14, (a) is the waveform of simulation and (b) is the waveform of experiment.

5.1. Elimination of "Dead Spot". Pick-up voltage with a symmetric magnetic circuit is illustrated in Figure 9. From Figure 9, it is evident that the primary-to-pick-up mutual inductances are approximately equal; therefore, the induced voltage, $u_{\mathrm{OC}}$, will become zero if the pick-up coils are placed in the center of three-phase primary coils. Figure 10 shows the pick-up voltage $u_{\mathrm{OC}}^{\prime}$ with an asymmetric magnetic circuit. Even if the load is placed in the center of three-phase primary coils, the induced voltage $u_{\mathrm{OC}}^{\prime}$ is not zero. Comparing Figure 9 with Figure 10, the proposed three-phase WPT system with an asymmetric magnetic circuit can effectively eliminate the pick-up voltage "dead spots."

5.2. Parameter Verification. Figure 11 shows the voltage and current waveforms of capacitor $C_{S}$ in asymmetric system (Figure 3). As evident from the illustration, the waveform of the voltage and current is not distorted. And its frequency and amplitude are very stable so that the parameters of the system are designed properly. 


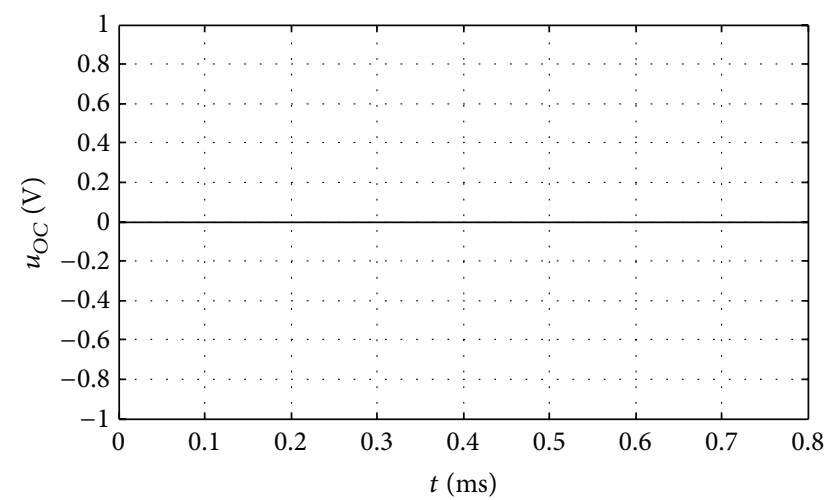

(a) Simulation

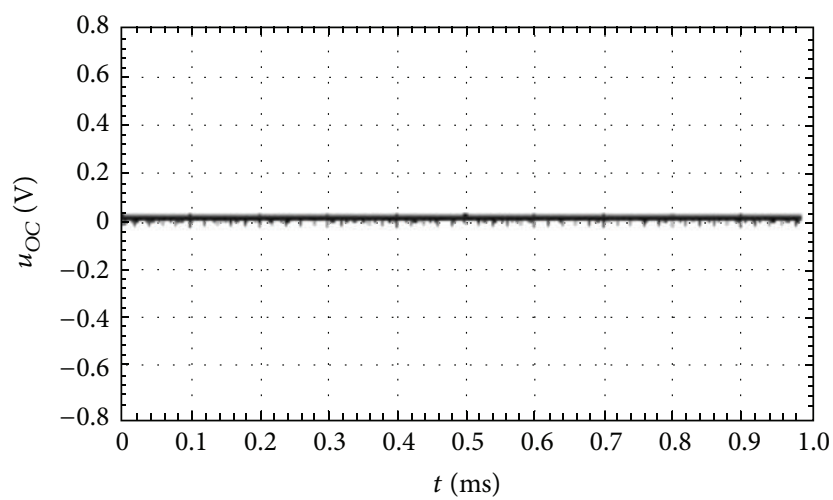

(b) Experiment

FIGURE 9: Pick-up voltage of secondary coil with symmetric magnetic circuit.

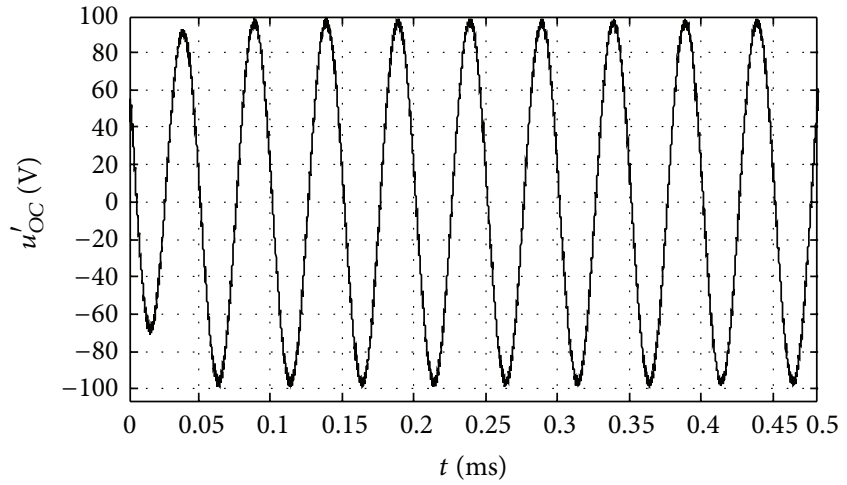

(a) Simulation

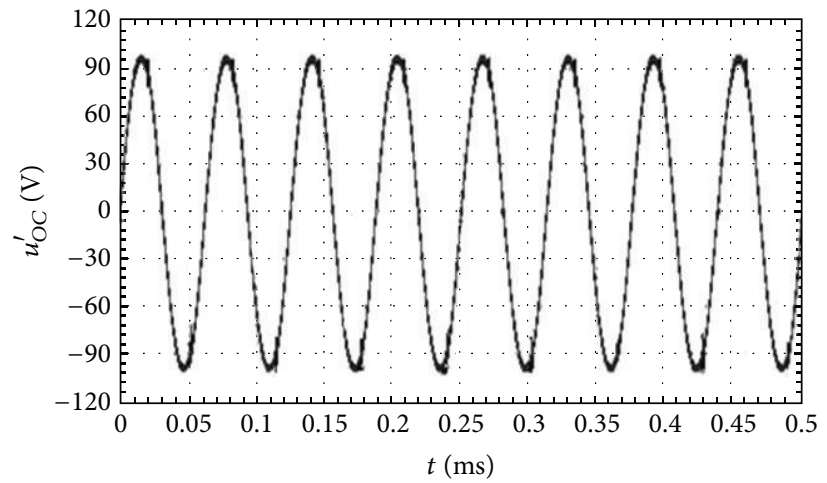

(b) Experiment

FIGURE 10: Pick-up voltage of secondary coil with asymmetric magnetic circuit.

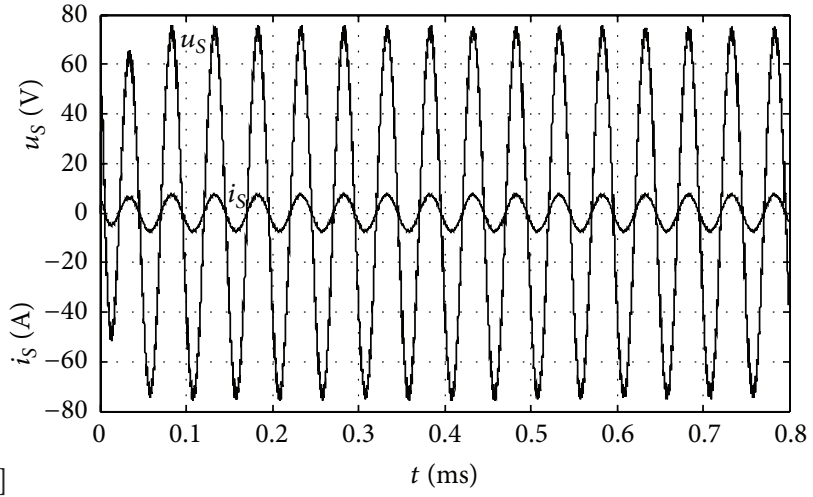

(a) Simulation

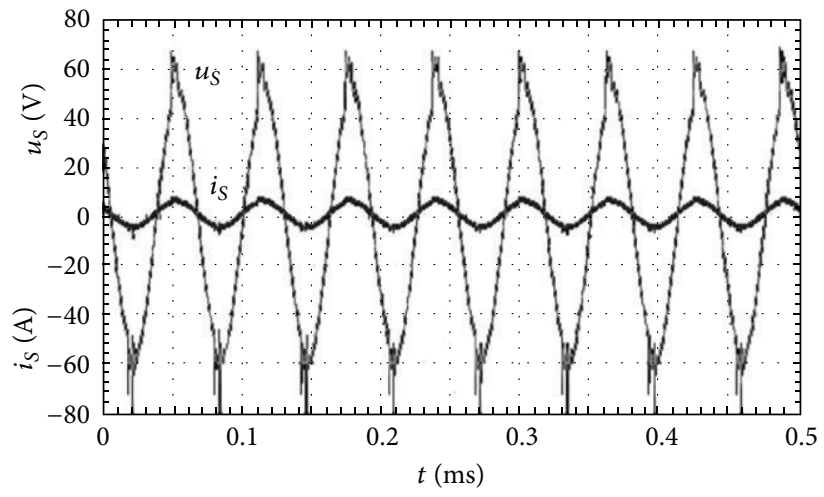

(b) Experiment

FIGURE 11: Voltage and current of capacitor $C_{S}$ in asymmetric system.

5.3. Impedance Conversion. From (16), when the value of load $R_{\mathrm{eq}}$ is $100 \Omega$, the system in Figure 3 will be in the nonresonant state for existing values of inductors and capacitors if any impedance conversion circuit is not added to the system. Then, the voltage waveform of pick-up coil is shown in Figure 12.
Obviously, the waveform of current has apparent distortion and high harmonic percentages. In this case, the transmission efficiency is low.

In order to achieve the frequency stability of asymmetric three-phase WPT system, impedance conversion is adopted in secondary side which is shown in Figure 6, and the 


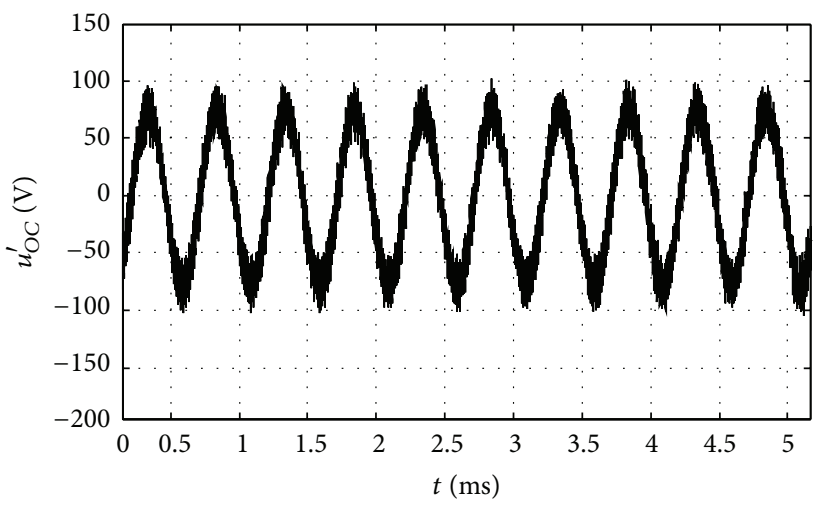

(a) Simulation

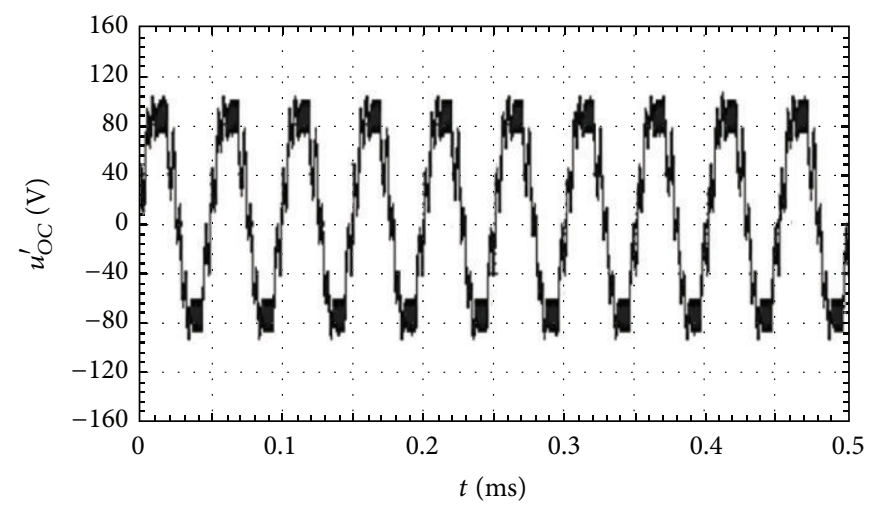

(b) Experiment

FIGURE 12: Voltage of pick-up coil when $R_{\text {eq }}$ equals $100 \Omega$.

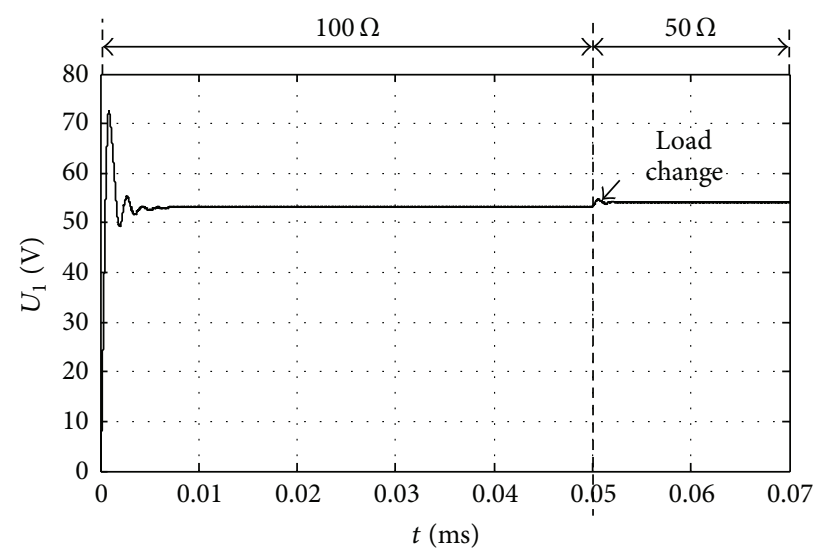

(a) Simulation

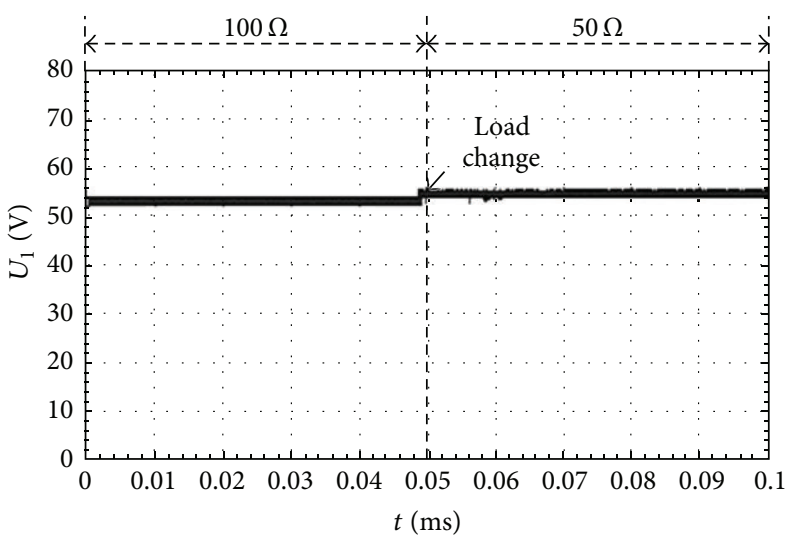

(b) Experiment

FIGURE 13: Input voltage before impedance conversion circuit.

topology of primary side remains the same. In addition, $R_{L}$ is $100 \Omega, C_{1}$ is $220 \mu \mathrm{F}, L_{b}$ is $3.9 \mathrm{mH}$, and $C_{b}$ is $10 \mu \mathrm{F}$.

Figure 13 shows the voltage waveform $U_{1}$ which is before impedance conversion circuit. From Figure 13, the load changes from $100 \Omega$ to $50 \Omega$ at 0.05 s. Meanwhile, according to (21), duty cycle $\delta$ of switch $S_{7}$ is changed from 0.741 to 0.649 for maintaining constant equivalent load $R_{\text {eq }}$ in Figure 6. The DC voltage $U_{1}$ remains stable after dynamic change in a period of time, which means reflected impedances from secondary side to primary side maintain being constant. $U_{1}$ rises to $54 \mathrm{~V}$ after load change. However, the error is about $1.48 \%$, which indicates that the pick-up voltage holds stable basically after adding the impedance conversion circuit.

In conclusion, the input voltage $U_{1}$ and impedance $R_{1}$ of impedance conversion circuit in Figure 6 can be unchanged by adjusting duty cycle $\delta$ at the time of load change. So, the output power of load $R_{L}$ will be stable according to (17) whether $R_{L}$ is changed or not.

Figure 14 shows the voltage waveform of load $R_{L}$. Comparing Figure 14(a) with Figure 14(b), the output voltage lowers in actual system because of the existence of parasitic resistances which are ignored in calculation and simulation.
From Figure 14(b), the output power is $201.64 \mathrm{~W}$ while it reduces to $200 \mathrm{~W}$ after load change. However, the error is only $0.8 \%$, which indicates that the output power of system can maintain being constant.

According to the above analysis, the proposed system improves frequency stability and efficiency by applying impedance conversion circuit into three-phase WPT system.

\section{Conclusion}

Aimed at the problem of "dead spot" in symmetric threephase WPT system, a three-phase WPT system with an asymmetric magnetic circuit has been presented. The parameters of the system are designed and optimized. However, there is a one-to-one correspondence between corresponding direct parameters (inductances and capacitances) and a load value. It means the system will be in nonresonant state if the load is changed, which causes low efficiency and high total harmonic distortion. But, in fact, the value of load is usually variational due to heat and temperature variation. So, common platform is more meaningful for three-phase WPT system. As transfer power and efficiency are greatly affected 


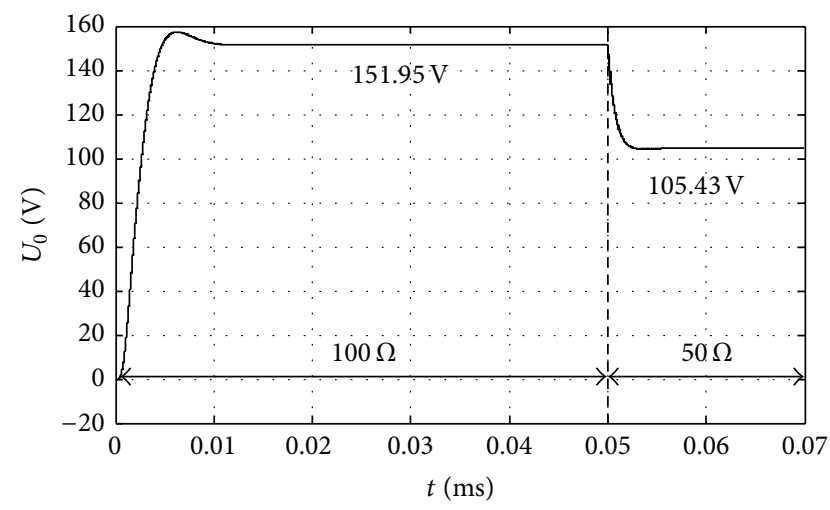

(a) Simulation

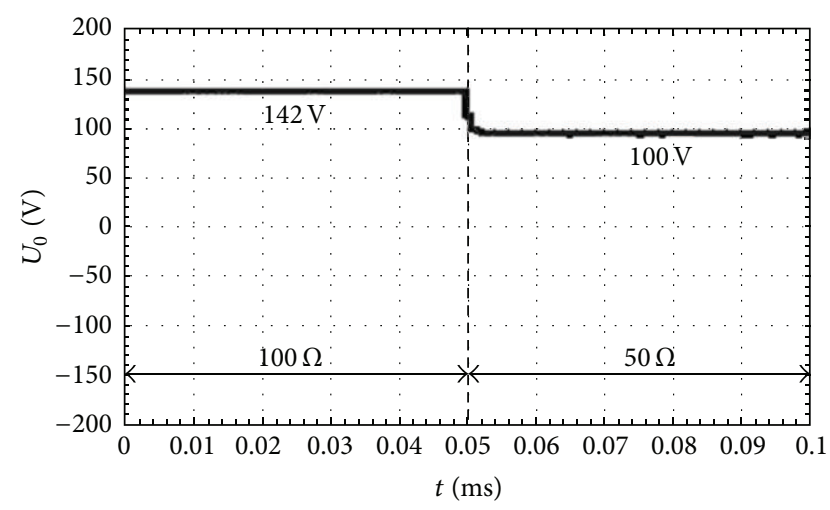

(b) Experiment

FigURE 14: Output voltage of load $R_{L}$.

by load change, a fixed frequency design method based on impedance conversion is proposed and correlation theory is derived in detail. So far, a three-phase WPT system has been designed which has advantages of stable operating frequency, high efficiency, and no "dead spot."

\section{Competing Interests}

The authors declare that there are no competing interests regarding the publication of this paper.

\section{Acknowledgments}

The authors would like to acknowledge project support by the National Science Foundation of China (Grant no. 51307173).

\section{References}

[1] Z. Pantic, K. Lee, and S. M. Lukic, "Multifrequency inductive power transfer," IEEE Transactions on Power Electronics, vol. 29, no. 11, pp. 5995-6005, 2014.

[2] H. Hao, G. A. Covic, and J. T. Boys, "A parallel topology for inductive power transfer power supplies," IEEE Transactions on Power Electronics, vol. 29, no. 3, pp. 1140-1151, 2014.

[3] W. Fu, B. Zhang, and D. Qiu, "Maximum efficiency analysis and design of self-resonance coupling coils for wireless power transmission system," Proceedings of the CSEE, vol. 29, no. 18, pp. 21-26, 2009.

[4] F. Musavi and W. Eberle, "Overview of wireless power transfer technologies for electric vehicle battery charging," IET Power Electronics, vol. 7, no. 1, pp. 60-66, 2014.

[5] F.-X. Yang, Y. Sun, and X. Dai, "Simulation of multi-load inductive coupled power bidirectional transfer mode," Journal of Central South University: Science and Technology, vol. 43, no. 10, pp. 3865-3871, 2012.

[6] Y. Zhou, W. Xia, and Y. Zhou, "Safety charging mode analysis with multi-load used in coal mine," in Proceedings of the International Conference on Materials for Renewable Energy and Environment (ICMREE '11), pp. 752-757, Shanghai, China, May 2011.

[7] H. Kim, J. Cho, S. Ahn, J. Kim, and J. Kim, "Suppression of leakage magnetic field from a wireless power transfer system using ferrimagnetic material and metallic shielding," in Proceedings of the IEEE International Symposium on Electromagnetic Compatibility (EMC '12), pp. 640-645, IEEE, Pittsburgh, Pa, USA, August 2012.

[8] M. Budhia, G. Covic, and J. Boys, "Magnetic design of a threephase inductive power transfer system for roadway powered electric vehicles," in Proceedings of the IEEE Vehicle Power and Propulsion Conference (VPPC '10), pp. 1-6, Lille, France, September 2010.

[9] R. Arnold and P. Gratzfeld, "Automatic tuning concept for a three-phase inductive power transfer system," in Proceedings of the 4th International Electric Drives Production Conference (EDPC '14), pp. 1-7, IEEE, Nuremberg, Germany, October 2014.

[10] D. J. Thrimawithana and U. K. Madawala, "A three-phase bi-directional IPT system for contactless charging of electric vehicles," in Proceedings of the IEEE International Symposium on Industrial Electronics (ISIE '11), pp. 1957-1962, Gdańsk, Poland, June 2011.

[11] G. A. Covic, J. T. Boys, M. L. G. Kissin, and H. G. Lu, "A threephase inductive power transfer system for roadway-powered vehicles," IEEE Transactions on Industrial Electronics, vol. 54, no. 6, pp. 3370-3378, 2007.

[12] C. L. W. Sonntag, E. A. Lomonova, and J. L. Duarte, "Power transfer stabilization of the three-phase contactless energy transfer by means of coil commutation," in Proceedings of the 4th IEEE Young Researchers Symposium in Electrical Engineering, pp. 1-6, Eindhoven, The Netherlands, February 2008.

[13] C. L. W. Sonntag, E. A. Lomonova, and J. L. Duate, Active Magnetic Field Shaping in the Variable-Phase Contactless Energy Transfer Desktop, Eindhoven University of Technology, Eindhoven, Netherlands, 2008.

[14] M. Kim, S. Ahn, and H. Kim, "Magnetic design of a threephase wireless power transfer system for EMF reduction," in Proceedings of the IEEE Wireless Power Transfer Conference (WPTC '14), pp. 17-20, IEEE, Jeju, South Korea, May 2014.

[15] H. Matsumoto, Y. Neba, K. Ishizaka, and R. Itoh, "Model for a three-phase contactless power transfer system," IEEE Transactions on Power Electronics, vol. 26, no. 9, pp. 2676-2687, 2011.

[16] X. Chen, Y. Zhang, and Y. Wang, "A study of dynamic interaction between PV grid-connected inverters and grid based on the impedance analysis method," Proceedings of the CSEE, vol. 34, no. 27, pp. 4559-4567, 2014. 
[17] Z. Yingnan, W. Junping, and Z. Xia, "Maximum power point tracking control in the photovoltaic power generation based on dynamic equivalent impedance matching theory," Proceedings of the CSEE, vol. 31, no. 2, pp. 111-118, 2011.

[18] C. Y. Xia, J. Zhang, N. Jia, Y. H. Zhuang, and X. J. Wu, "Asymmetric magnetic unit of three-phase IPT system for achieving effective power transmission," Electronics Letters, vol. 49, no. 11, pp. 717-719, 2013.

[19] R. L. Steigerwald, "A comparison of half-bridge resonant converter topologies," IEEE Transactions on Power Electronics, vol. 3, no. 2, pp. 174-182, 1988. 


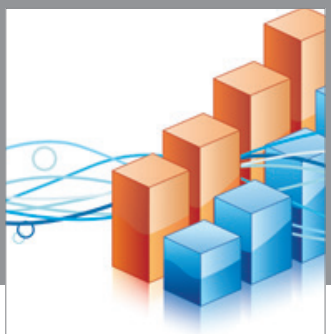

Advances in

Operations Research

vatem alat4

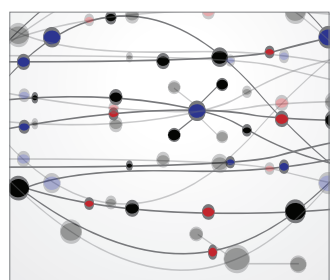

\section{The Scientific} World Journal
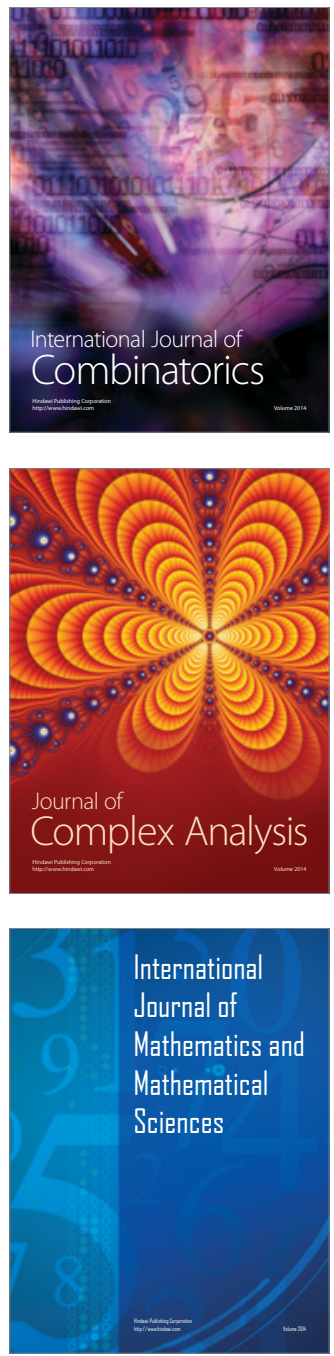
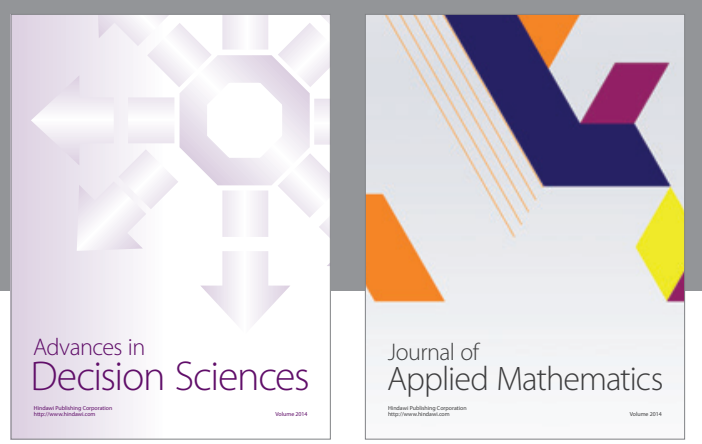

Algebra

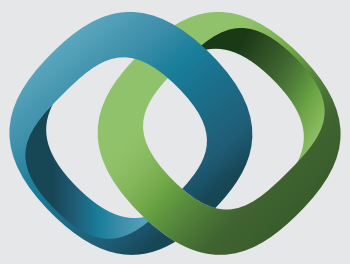

\section{Hindawi}

Submit your manuscripts at

http://www.hindawi.com
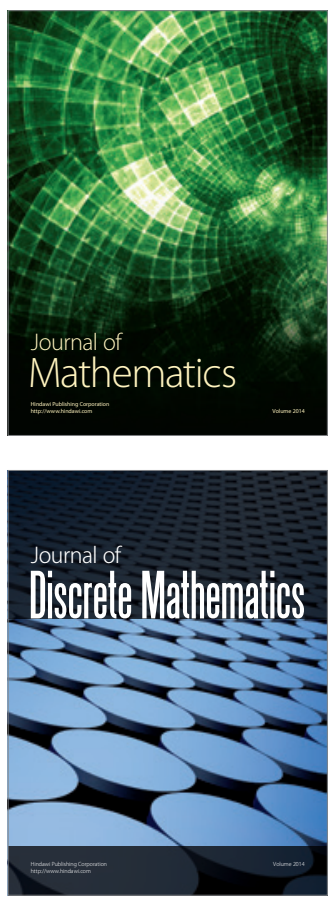

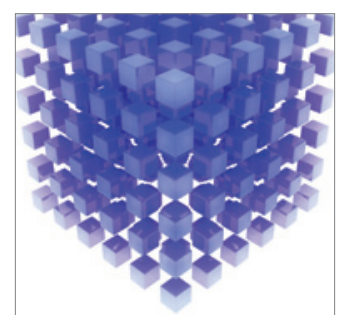

Mathematical Problems in Engineering
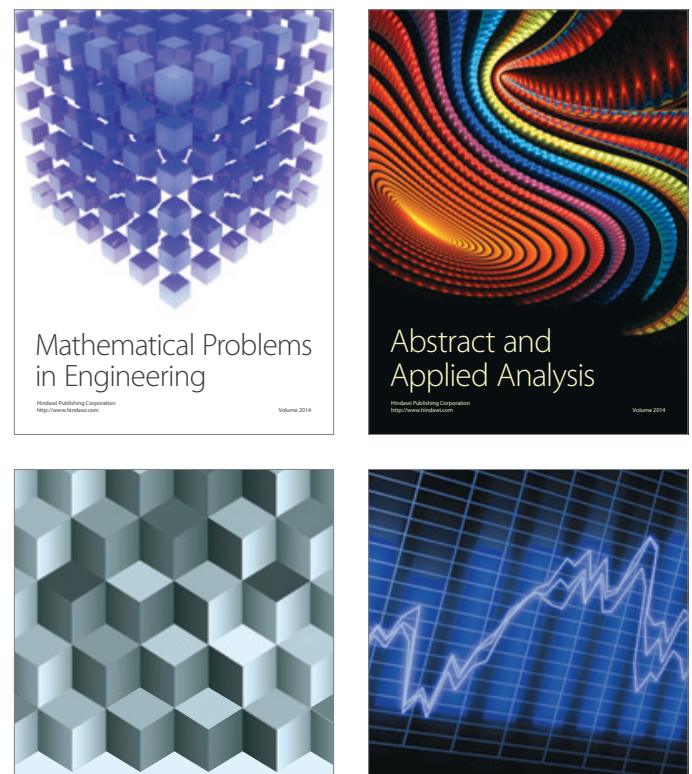

Journal of

Function Spaces

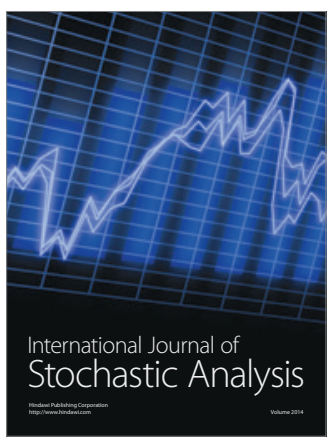

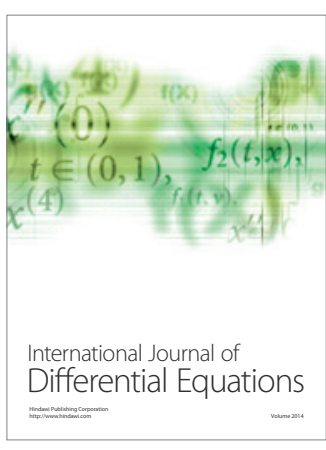
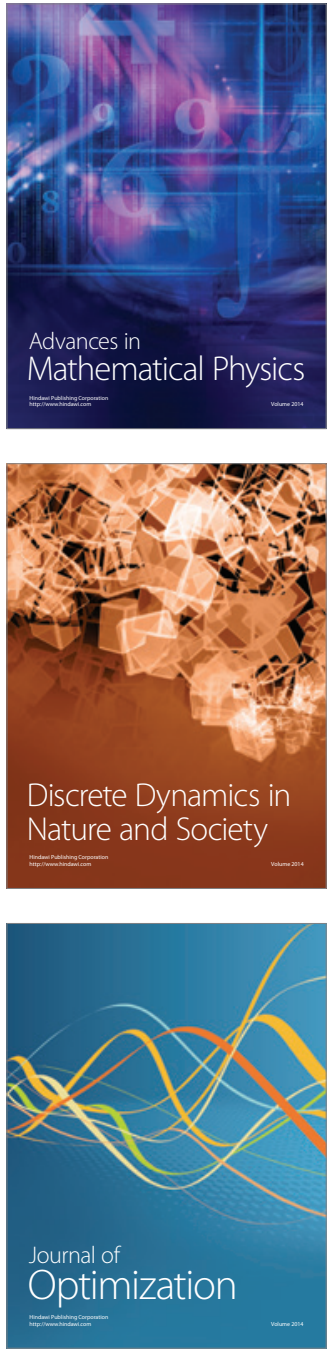